\title{
Work-Life Balance and Labor Force Attachment at Older Ages
}

Marco Angrisani, Maria Casanova,and Erik Meijer

Project \#: UM17-11 


\title{
Work-Life Balance and Labor Force Attachment at Older Ages
}

\author{
Marco Angrisani \\ University of Southern California \\ Maria Casanova \\ California State University-Fullerton \\ Erik Meijer \\ University of Southern California
}

September 2017

\author{
Michigan Retirement Research Center \\ University of Michigan \\ P.O. Box 1248 \\ Ann Arbor, MI 48104 \\ www.mrrc.isr.umich.edu \\ (734) 615-0422
}

\section{Acknowledgements}

The research reported herein was performed pursuant to a grant from the U.S. Social Security Administration (SSA) funded as part of the Retirement Research Consortium through the University of Michigan Retirement Research Center Award RRC08098401-09. The opinions and conclusions expressed are solely those of the author(s) and do not represent the opinions or policy of SSA or any agency of the federal government. Neither the United States government nor any agency thereof, nor any of their employees, makes any warranty, express or implied, or assumes any legal liability or responsibility for the accuracy, completeness, or usefulness of the contents of this report. Reference herein to any specific commercial product, process or service by trade name, trademark, manufacturer, or otherwise does not necessarily constitute or imply endorsement, recommendation or favoring by the United States government or any agency thereof.

\section{Regents of the University of Michigan}

Michael J. Behm, Grand Blanc; Mark J. Bernstein, Ann Arbor; Shauna Ryder Diggs, Grosse Pointe; Denise Ilitch, Bingham Farms; Andrea Fischer Newman, Ann Arbor; Andrew C. Richner, Grosse Pointe Park; Ron Weiser, Ann Arbor; Katherine E. White, Ann Arbor; Mark S. Schlissel, ex officio 


\title{
Work-Life Balance and Labor Force Attachment at Older Ages
}

\begin{abstract}
We use data from the Health and Retirement Study to examine the role of work-life balance (WLB) as a nonmonetary determinant of retirement transitions, conditional on job attributes such as hours of work, compensation, and benefits. We show that low levels of WLB are significantly associated with subsequent reductions in labor supply for workers ages 51 to 79, and document heterogeneity by gender and employment status. Moreover, WLB mediates labor supply responses to spousal health shocks. Workers who report higher levels of work-to-life interference are significantly more likely to reduce their labor supply in the next two periods following a spouse's health shock, and this effect is once more heterogeneous. The moderating effect of WLB is stronger for women than men. Among female workers, it is stronger for those employed part-time at baseline.
\end{abstract}

\section{Citation}

Angrisani, Marco, Maria Casanova, and Erik Meijer. 2017. "Work-Life Balance and Labor Force Attachment at Older Ages.” Ann Arbor MI: University of Michigan Retirement Research Center (MRRC) Working Paper, WP 2017-366. http://mrrc.isr.umich.edu/wp366/

\section{Authors' acknowledgements}

This research was funded by the U.S. Social Security Administration through the University of Michigan Retirement Research Center (UM17-11). We thank participants at the MRRC Researcher Workshop 2017 and the 19th Annual Meeting of the Retirement Research Consortium, especially our discussant Matt Rutledge, for helpful comments and discussion. Corresponding author; marco.angrisani@usc.edu 


\section{Introduction}

Demographic trends over the last five decades have led to longer life expectancies and declining birth rates. The resulting concerns about the long-term sustainability of Social Security programs have focused attention on understanding what drives individuals' retirement decisions and on how to increase older workers’ labor force attachment (Wise, 2010).

Traditionally, economic analyses of retirement have focused on key determinants of labor supply choices such as monetary incentives — from Social Security rules (Blau and Goodstein, 2010; Gruber and Wise, 2004; French, 2005), private pension arrangements (Goda et al., 2017; Lumsdaine and Mitchell, 1999), and the availability of health insurance (French and Jones, 2011)—and health shocks (Currie and Madrian, 1999; McGeary, 2009). But the relative (dis)utility of work is also driven by nonmonetary job characteristics such as job satisfaction, hours flexibility, physical and cognitive demands of the job, etc. (Angrisani et al., 2015, 2017; Clark and Oswald, 1996; Flabbi and Moro, 2012; Lévy-Garboua et al., 2007; Sullivan and To, 2014).

A growing literature has identified work-life balance (WLB), defined as the absence of conflict between work and nonwork activities, as a nonmonetary determinant of the relative attractiveness of work versus leisure, particularly at older ages (Bianchi and Milkie, 2010; Gardiner et al., 2007; Guest, 2002; Raymo and Sweeney, 2006). Workers whose jobs allow them to more easily manage their private life (children, doctor visits, caring for an elderly parent or sick spouse, etc.) may be more likely to remain employed than those who perceive that their jobs interfere with their personal lives.

A better understanding of the effect of WLB on retirement behavior, and of the specific life circumstances during which WLB becomes valuable to employees, provides a policy handle to affect workplace arrangements so as to facilitate longer labor force attachment at older ages. This line of research is particularly timely in view of the increase in women's labor force participation in the past 
decades, which has led to a growing number of female workers on the verge of retirement. Because of existing social norms related to gender roles, women are typically more sensitive to the trade-off between career and family life (Lewis, 2008). At the same time, late fertility and longer life expectancy have placed more responsibility on middle-aged/older workers for supporting their own children and caring for their aging parents, thus increasing the strain on WLB.

In this paper, we use data from the Health and Retirement Study (HRS) to investigate the relationship between WLB and retirement transitions. We use a sample of workers ages 51 to 79 to assess the association between perceived WLB at a given point in time with subsequent employment choices. We perform our analysis separately for men and women to explore the possibility of differential labor supply responses by gender. Because of the prevalence of partial retirement, and given that parttime work may be an important alternative to retirement in the face of work-life interference, we distinguish between full-time and part-time workers. Moreover, in our analysis, we jointly account for work strains that affect one's private life negatively (work-to-life interference, or WLI) and aspects of one's private life that may negatively impact one’s productivity or work (dis)utility (life-to-work interference, or LWI).

Additionally, we explore the extent to which WLB interacts with life circumstances in determining retirement decisions. For example, a spouse's or elderly parent's health shock or the birth of a grandchild may increase the importance of time off for care giving. Individuals whose jobs do not afford them the option to easily juggle family responsibilities may be inclined to retire early following such events. We investigate this possibility by studying how responses to a spouse's health shock differ by WLB levels before the onset of the shock. In view of previous research documenting gender differences in the responses to family members' health shocks (Coile, 2004; McGeary, 2009), we perform the analysis separately for men and women.

Our results show that WLB is significantly associated with labor force transitions among older workers. The effect is largely driven by work-to-life conflict. Specifically, workers who report higher 
levels of WLI are more likely to retire within the next two years. This trend is observed for both fulland part-timers, and is stronger for women than for men. Instead, life-to-work conflict has no effect on the labor supply of full-time workers. For part-timers, higher levels of LWI are associated with a higher likelihood of remaining in part-time work, although this effect is only marginally significant. Moreover, the net effect on labor supply is ambiguous, as part-time workers who report high LWI are both slightly less likely to transition into full-time work and to retire within the next two years.

We find that WLB moderates labor supply responses to a spouse’s health shock. For male workers, the likelihood that full-timers remain in full-time employment following a spouse's health shock decreases as WLI increases, while there is no moderating effect of WLB for part-timers. Among women, labor supply responses to a spouse's health shock are stronger and interactions with WLB more apparent. Both full- and part-time female workers are more likely to decrease their labor supply in response to a deterioration in the health of their spouse when baseline WLI levels are high.

Previous research has suggested a potential link between WLB and retirement behavior by showing that full-time workers in their early 50s who experience low levels of WLB are more likely to report a preference for retiring within the next 10 years (Raymo and Sweeney, 2006). Our study is the first to address and quantify the association between WLB and actual employment transitions of middle-aged and older workers.

A further contribution of our study is to establish that life circumstances affect an individual's willingness to tolerate the absence of WLB, as hypothesized by Guest (2002). Specifically, it shows how WLB moderates labor supply responses to spousal health shocks.

A limitation of our study is the lack of a strong source of exogenous variation in WLB, which may raise concerns about selection effects. As we will argue in more detail, our results are to be viewed as lower bound estimates of the effect of WLB on older workers' labor supply decisions. In fact, the most likely form of selectivity would lead to individuals with a high preference for leisure, who are more likely to retire, to sort into jobs with better WLB, thereby dampening the effect of WLB on retirement. 
The remaining of the paper proceeds as follows. Section 2 introduces the data and the measures of WLB used in the analysis. Section 3 describes the empirical methodology and presents the results. Section 4 concludes.

\section{Data and descriptive statistics}

We use data from the Health and Retirement Study (HRS), a multipurpose, longitudinal household survey representing the U.S. population older than 50. Since 1992, the HRS has surveyed age-eligible respondents and their spouses every two years to track transitions from work into retirement, to measure economic well-being in later life, and to monitor changes in health status as individuals age. Initially, the HRS consisted of individuals born between 1931 and 1941 and their spouses, but additional cohorts have been added in 1993, 1998, 2004, and 2010, the youngest representing individuals born between 1954 and 1959.

We primarily use data from the RAND version of the HRS, version P (Bugliari et al., 2016). The RAND HRS is a large, user-friendly subset of the HRS that combines data from all waves, adds information that may have been provided by the spouse to the respondent's record and has consistent imputation of financial variables. We complement this data set with additional variables from the employment module of each wave obtained from the RAND FAT files. These are partially preprocessed files with all the raw HRS data of each wave combined into a single, respondent-level file.

In 2004, the HRS piloted a supplemental self-administered questionnaire that was left with the respondent after the completion of an in-person core interview. This Leave-Behind (LB) Questionnaire elicits respondents’ evaluations of their life circumstances, subjective well-being, and lifestyle. Since 2004, the LB questionnaire has been administered in each biennial wave to a randomly selected, rotating 50 percent of the core sample who were assigned to an in-person interview. This design implies that, for each respondent, LB measures are available every other wave (or every four years). Importantly for our 
purpose, in 2006 a number of questions about work-to-life and life-to-work interference were introduced in the LB instrument (see below).

We include individuals ages 51 to 79 in our analysis sample, spanning the period 2006-2014. The HRS core questionnaire provides us with information about individual demographics and household characteristics, labor force status, pension arrangements, financial situation, health status, and retirement expectations. We follow Maestas (2010) and Angrisani et al. (2015) and classify individuals as full-time employees if they work at least 35 hours per week on their main job and as part-time employees if they work less than 35 hours per week on their main job. We classify individuals as "retired" if they do not work for pay. We exclude from the sample anyone who is self-employed, disabled, unemployed or out of the labor force for reasons other than retirement according to the RAND HRS labor force status definition.

The outcome of interest is the wave-to-wave transition between these labor force states. We cannot consider transitions from complete retirement back to work, as work-life balance measures are not available for retirees. ${ }^{1}$ There are 2,448 male and 3,011 female workers with valid transitions for a total of 3,036 and 3,833 observations, respectively. Table 1 shows the prevalence of labor force transitions aggregated across all waves by current employment status and gender. The majority of full-time employees are still employed full-time in the subsequent wave, with women more likely to transit into part-time than men. Among part-timers, male workers are relatively more likely to move to full-time and to retire the next period, while female workers are more likely to remain employed part-time. Given this observed heterogeneity in labor supply decisions, in what follows we will perform our analyses separately for full- and part-timers as well as for men and women.

\footnotetext{
${ }^{1}$ Maestas (2010) explicitly studies transitions from retirement to work, a phenomenon known as "unretirement."
} 
Table 1: Labor force transitions by current employment status and gender

\begin{tabular}{lcccc}
\hline Labor force status at time $\boldsymbol{t}$ & \multicolumn{2}{c}{ Labor force status at time $\boldsymbol{t + 1}$} & \multirow{2}{*}{ Total } \\
\cline { 2 - 3 } Men & Full-time & Part-time & Retired & \\
Full-time & 1,882 & 175 & 297 & 2,354 \\
& $(79.95 \%)$ & $(7.43 \%)$ & $(12.62 \%)$ & $(100.00 \%)$ \\
Part-time & 94 & 437 & 151 & 682 \\
& $(13.78 \%)$ & $(64.08 \%)$ & $(22.14 \%)$ & $(100.00 \%)$ \\
Total & 1,976 & 612 & 448 & 3,036 \\
& $(65.09 \%)$ & $(20.16 \%)$ & $(14.76 \%)$ & $(100.00 \%)$ \\
Women & & & & 2,478 \\
Full-time & 1,893 & 250 & 335 & $(100.00 \%)$ \\
& $(76.39 \%)$ & $(10.09 \%)$ & $(13.52 \%)$ & 1,355 \\
Part-time & 159 & 922 & 274 & $(100.00 \%)$ \\
& $(11.73 \%)$ & $(68.04 \%)$ & $(20.22 \%)$ & 3,833 \\
Total & 2,052 & 1,172 & 609 & $(100.00 \%)$ \\
\hline
\end{tabular}

The HRS core questionnaire asks respondents currently working for pay about several aspects of their jobs. These include information about employer-provided pension plans and health insurance, earnings, hours of work per week, and nonmonetary characteristics. We will study to what extent WLB influences employment transitions of older workers keeping monetary incentives and other potential confounders constant. The richness of information available in the HRS also allows us to control for the economic, health, and family circumstances that are bound to affect labor supply decisions at older ages.

Table 2 presents descriptive statistics of the variables used in the analysis. Men are slightly older than women on average, reflecting that men retire at older ages. Among male workers, full-timers are about six years younger than part-timers, while this difference is four years for women. Our sample covers a broad range of educational backgrounds and other demographic characteristics. Male workers are more commonly in a couple than female workers. Men who work full-time more often have a 
working spouse than men who work part-time, whereas there is no detectable difference among women. Men work more hours per week and are better paid than women. Total household wealth is, on average, larger among men than women respondents. Not surprisingly, employer-provided pension plans and health insurance coverage are substantially more common among full-time than part-time workers.

\subsection{Measuring work-life balance}

WLB can be loosely defined as the availability of "sufficient time to meet commitments both at home and at work" (Guest, 2002). Because of the difficulty of measuring WLB directly, we follow the existing literature on this topic and focus on its absence, that is, instances of interference between work and life outside of work.

The conflict between work and life is bidirectional. Work-to-life interference (WLI) describes situations where the demands from work (e.g., long working hours, inflexible schedules, expectations of constant availability, etc.) interfere with life outside of work. For example, the need to work overtime may prevent a worker from accompanying their sick spouse to a doctor's appointment. Life-to-work interference (LWI) arises when nonwork burdens — such as the needs of adult children, caregiving to elderly parents and sick spouses, or strained spousal relationships — spill over into work life. Along these lines, an individual's productivity on the job may decline while, for instance, they provide care for an elderly parent or a sick spouse. We consider both dimensions separately in our analysis.

It has been proposed that WLB can be measured by both objective indicators, such as the number of hours worked, and subjective indicators, such as individuals' self-reports of the degree of conflict between their work and family lives (Guest, 2002). In practice, though, it is difficult to produce objective indicators of WLI or LWI without relying on strong assumptions about what constitutes worklife balance. For instance, using an indicator of working long hours as a proxy for WLI reflects an assumption that all workers assign a relatively similar weight to work and home life, even though some workers derive great satisfaction from working 60-hour weeks and would not perceive this as an 
intrusion into their family life (Peiperl and Jones, 2001). In our analysis, we focus on subjective measures of WLB, while controlling for more objective job attributes such as hours of work, compensation, and benefits.

Table 2: Means of individual characteristics by gender and initial labor force status

\begin{tabular}{lrrrrrr}
\hline Characteristic & \multicolumn{2}{c}{ Men } & & \multicolumn{2}{c}{ Women } \\
\cline { 2 - 3 } \cline { 5 - 6 } Demographics, health, and wealth & Full-time & Part-time & & Full-time & Part-time \\
\hline Age & 59.17 & 65.43 & & 58.25 & 62.24 \\
Less than high school & 0.12 & 0.14 & & 0.11 & 0.15 \\
High school & 0.25 & 0.23 & & 0.27 & 0.30 \\
Some college & 0.27 & 0.24 & & 0.31 & 0.29 \\
College and above & 0.36 & 0.39 & & 0.31 & 0.25 \\
In a couple & 0.84 & 0.84 & & 0.64 & 0.67 \\
Spouse working & 0.58 & 0.44 & & 0.44 & 0.44 \\
Poor health & 0.12 & 0.14 & & 0.13 & 0.15 \\
Word recall score & 0.04 & -0.15 & & 0.02 & -0.04 \\
Serial 7s score & 0.00 & -0.01 & & 0.02 & -0.03 \\
Total hh wealth (in 1,000 \$) & 517.63 & 737.37 & & 356.47 & 503.20 \\
Work & & & & & \\
Hours of work per week & 45.69 & 21.06 & & 42.69 & 20.83 \\
Hourly wage (in \$) & 29.38 & 38.19 & & 22.76 & 21.44 \\
DB pension & 0.23 & 0.06 & & 0.25 & 0.09 \\
DC pension & 0.38 & 0.15 & & 0.41 & 0.16 \\
No pension & 0.39 & 0.79 & & 0.34 & 0.74 \\
Empl. health ins. & 0.68 & 0.34 & & 0.72 & 0.27 \\
Empl. health ins. covers Sp & 0.37 & 0.21 & & 0.22 & 0.07 \\
Work-life balance & & & & & \\
Work-Life Interference (WLI) & 0.21 & -0.72 & & 0.33 & -0.60 \\
Life-Work Interference (LWI) & 0.05 & -0.17 & & 0.11 & -0.19 \\
N & 2,354 & 682 & & 2,478 & 1,355 \\
\hline
\end{tabular}

Note. WLI, LWI, word recall, and Serial 7s scores are standardized. 
Table 3: Work-Life Balance measures elicited by the LB questionnaire

\begin{tabular}{|c|c|}
\hline Question & Text \\
\hline LB048A & My work schedule makes it difficult to fulfill personal responsibilities \\
\hline LB048B & $\begin{array}{l}\text { Because of my job, I don't have the energy to do things with my family } \\
\text { or other important people in my life }\end{array}$ \\
\hline LB048C & Job worries or problems distract me when I am not at work \\
\hline LB048D & My home life keeps me from getting work done on time on my job \\
\hline LB048E & My family or personal life drains me of the energy I need to do my job \\
\hline LB048F & I am preoccupied with personal responsibilities while I am at work \\
\hline LB048G & My work leaves me enough time to attend to my personal responsibilities \\
\hline LB048H & $\begin{array}{l}\text { My work gives me energy to do things with my family and other } \\
\text { important people in my life }\end{array}$ \\
\hline LB048I & Because of my job, I am in a better mood at home \\
\hline LB048J & My personal responsibilities leave me enough time to do my job \\
\hline LB048K & My family or personal life gives me energy to do my job \\
\hline LB048L & I am in a better mood at work because of my family or personal life \\
\hline
\end{tabular}

The measures of WLI and LWI used in this paper are based on answers to a series of questions eliciting the perceived conflict between an individual's work and personal life. These questions are listed in Table 3. Answers are given on the following four-point scale: $1=$ rarely, 2 = sometimes, $3=$ often, and $4=$ most of the time. We reverse-code questions LB048G through L, so that higher values indicate more interference between work and life for all variables.

We create two indexes measuring WLI and LWI as the first principal component of the subset of variables that reflect each concept. For WLI, these are LB048A, LB048B, LB048C, LB048G, LB048H, and LB048I; for LWI, these are LB048D, LB048E, LB048F, LB048J, LB048K, and LB048L. The indexes are standardized to have a mean of 0 and a standard deviation of 1.

Both indexes display right-skewed distributions in the sample, with WLI ranging from -2.4 to 6.1, and LWI ranging from -1.6 to 10.4. Sample averages are reported at the bottom of Table 2. On average, full-time workers report higher levels of WLI and LWI than part-time workers. Among individuals working full-time, women report worse WLI and LWI than men, with differences significant at the 1 percent level. Among part-timers, women report higher levels of WLI and LWI as well, although only 
the difference in WLI levels is statistically significant. For both male and female workers, the WLI and LWI indexes exhibit a sample correlation of about 55 percent among full-timers and of 64 percent among part-timers.

In Table 4, we compare individuals with low and high WLB. For this purpose, we construct a combined index of work-life interference using both WLI and LWI measures and assign respondents to two groups depending on whether their index is below (low work-life interference) or above (high worklife interference) the sample median. Individuals with high interference tend to be a little younger and more likely to be in poor health than those reporting low interference, while there are no significant differences as far as marital status, education, and cognition are concerned. High work-life interference is associated with more hours of work, but with better economic conditions, especially among women. Female workers reporting relatively higher levels of conflict have slightly higher wages, are more likely to be enrolled in a pension plan, and are more likely to have employer-sponsored health insurance. Individuals with high interference have significantly less wealth—about 25 percent less among men and 15 percent less among women. While suggesting worse retirement preparedness, this may also be related to the relatively younger ages of part-timers compared to full-timers. 
Table 4: Differences between workers with low and high Work-Life Interference (WLI)

\begin{tabular}{|c|c|c|c|c|c|c|}
\hline \multirow[t]{2}{*}{ Characteristic } & \multicolumn{3}{|c|}{ Men } & \multicolumn{3}{|c|}{ Women } \\
\hline & $\begin{array}{c}\text { Low WLI } \\
\text { mean }\end{array}$ & $\begin{array}{c}\text { High WLI } \\
\text { mean }\end{array}$ & $\begin{array}{c}\text { Diff } \\
p \text {-val }\end{array}$ & $\begin{array}{l}\text { Low } \\
\text { WLI } \\
\text { mean } \\
\end{array}$ & $\begin{array}{c}\text { High WLI } \\
\text { mean }\end{array}$ & $\begin{array}{c}\text { Diff } \\
p \text {-val }\end{array}$ \\
\hline \multicolumn{7}{|c|}{ Demographics, health, and wealth } \\
\hline Age & 61.75 & 59.40 & 0.00 & 60.75 & 58.57 & 0.00 \\
\hline Less than high school & 0.12 & 0.13 & 0.62 & 0.12 & 0.14 & 0.21 \\
\hline High school & 0.24 & 0.24 & 0.70 & 0.29 & 0.27 & 0.10 \\
\hline Some college & 0.26 & 0.27 & 0.77 & 0.30 & 0.30 & 0.99 \\
\hline College and above & 0.38 & 0.36 & 0.35 & 0.28 & 0.29 & 0.49 \\
\hline In a couple & 0.85 & 0.83 & 0.06 & 0.65 & 0.66 & 0.80 \\
\hline Spouse working & 0.55 & 0.55 & 1.00 & 0.44 & 0.45 & 0.59 \\
\hline Poor health & 0.09 & 0.17 & 0.00 & 0.09 & 0.18 & 0.00 \\
\hline Word recall score & 0.02 & -0.02 & 0.35 & 0.01 & -0.01 & 0.44 \\
\hline Serial 7s score & 0.03 & -0.03 & 0.11 & 0.02 & -0.02 & 0.17 \\
\hline $\begin{array}{l}\text { Total hh wealth (in } 10,000 \\
\text { \$) }\end{array}$ & 656.40 & 477.58 & 0.00 & 442.77 & 373.90 & 0.00 \\
\hline \multicolumn{7}{|l|}{ Work } \\
\hline Hours of work per week & 37.39 & 42.92 & 0.00 & 32.02 & 37.91 & 0.00 \\
\hline Hourly wage (in \$) & 35.67 & 32.88 & 0.65 & 21.41 & 23.18 & 0.14 \\
\hline DB pension & 0.19 & 0.19 & 0.64 & 0.18 & 0.21 & 0.03 \\
\hline DC pension & 0.31 & 0.35 & 0.05 & 0.29 & 0.35 & 0.00 \\
\hline No pension & 0.50 & 0.46 & 0.03 & 0.53 & 0.44 & 0.00 \\
\hline Emp. health ins. & 0.58 & 0.63 & 0.01 & 0.51 & 0.60 & 0.00 \\
\hline Emp. health ins. covers Sp & 0.32 & 0.34 & 0.16 & 0.15 & 0.18 & 0.00 \\
\hline$N$ & 1,518 & 1,518 & 3,036 & 1,917 & 1,916 & 3,833 \\
\hline
\end{tabular}

Note. WLI, LWI, word recall, and Serial 7s scores are standardized. Low WLI: below median; High WLI: above median.

\subsection{Measuring a spouse's health shocks}

After establishing the effect of work-life balance and employment transitions in Section 3.1, we assess, in Section 3.2, to what extent this relationship is moderated by changes in family circumstances across two consecutive periods as represented by a spouse's health shock. To this end, we follow McClellan (1998), Coile (2004), and Smith (2005) and construct two indicator variables, one for the incidence of acute health issues between time $t$ and $t+1$, including heart problems, strokes, and cancer, and one for 
new diagnoses of chronic conditions such as diabetes, lung disease, high blood pressure, arthritis, and psychological problems. ${ }^{2}$ In our sample, only about 5 percent of workers have a spouse who suffers an acute health event, and 12.5 percent have a spouse who is newly diagnosed with a chronic condition across two consecutive periods. In order to prevent cell sizes from becoming too small when carrying out the analysis using the acute shock indicator separately by current employment status and gender, we consider a spouse experiencing a health shock if the individual either suffers an acute event or is newly diagnosed with a chronic condition.

For the analysis investigating the interaction between WLB and spousal health shocks in determining labor force transitions, we restrict the sample to couple households. After excluding respondents for whom spousal health information is missing, we are left with 2,443 male workers $(1,889$ employed full-time and 554 employed part-time at baseline) and 2,350 female workers (1,496 in fulltime employment and 854 in part-time employment at baseline).

\section{Empirical analysis and results}

A number of factors shape labor supply decisions at older ages, from compensation, pension arrangements, and health insurance coverage, to family circumstances, work capability, and job demands. Likely, these factors indirectly impact WLB and interact with it to determine the timing of and path to retirement. In our empirical analysis, we take advantage of detailed information on older workers and their spouses available in the HRS to estimate the effect of WLB on labor supply decisions above and beyond the effect of other potential determinants. Specifically, our regressions account for age, education, marital status, whether the spouse is working, and the spouse's health status. We proxy individual ability to work with self-reported health status and cognitive test scores. We control for jobspecific factors including hourly wage, existence and type of employer-sponsored pension plan (defined benefit, DB, and/or defined contribution, DC), whether the individual receives health insurance coverage

\footnotetext{
${ }^{2}$ Our results do not change when we exclude psychological problems from this definition.
} 
through the employer, and whether this coverage extends to the spouse. In addition, we include dummies for total household wealth quartiles to capture available resources to finance retirement, and time fixedeffects to net out trends in retirement behavior over the observation period.

We estimate multinomial discrete choice models for the transitions from full-time employment into part-time and retirement and for the transitions from part-time employment into full-time and retirement across two periods. This allows us to study a variety of retirement paths that have been observed among older American workers in recent years (Chan and Stevens, 2008). Moreover, recognizing the existence of potential gender differences in the preference for work versus leisure/household activities as well as in the perception of how work interferes with private life, we separately estimate our models for men and women.

Formally, we model the probability that a full-time or part-time worker observed at time $t$ transits to a different labor force status at time $t+1$ as:

$$
P_{i j, t+1}^{k}=\operatorname{Pr}\left(Y_{i, t+1}=j \mid X_{i, t}, W L B_{i, t}, Y_{i, t}=k\right)=F_{j}^{k}\left(X_{i, t}, W L B_{i, t} ; \theta^{k}\right),
$$

where $Y_{i, t+1}$ is the labor force status at time $t+1 ; j=1$ (full-time), 2 (part-time), 3 (retired); $X_{i, t}$ is a vector of explanatory variables observed at time $t ; W L B_{i, t}$ contains the two indexes measuring WLI and LWI at time $t$ (higher values of these indexes correspond to worse WLB); and the superscript $k$ indicates labor force status at time $t$ (either full-time, $k=1$, or part-time, $k=2$ ). Time $t=1,2,3,4$, corresponds with waves 8 (2006/2007), 9 (2008/2009), 10 (2010/2011), and 11 (2012/2013), respectively, of the HRS. The function $F_{j}^{k}$ is a probability function depending on a vector of unknown parameters $\theta^{k}$. We adopt a multinomial logit model, hence:

where

$$
F_{j}^{k}\left(X_{i, t}, W L B_{i, t} ; \theta^{k}\right)=\frac{\exp \left(V_{i j}^{k}\right)}{\sum_{l=1}^{3} \exp \left(V_{i l}^{k}\right)}, \quad j=1,2,3,
$$

$$
V_{i j}^{k}=X_{i, t}^{\prime} \alpha_{j}^{k}+W L B_{i, t}^{\prime} \beta_{j}^{k}
$$


and $\theta^{k} \equiv\left(\alpha_{2}^{k^{\prime}}, \beta_{2}^{k^{\prime}}, \alpha_{3}^{k^{\prime}}, \beta_{3}^{k^{\prime}}\right)^{\prime}$, with $\alpha_{1}^{k}$ and $\beta_{1}^{k}$ normalized to zero. To ease the notation, we omit a superscript for male and female workers. Nonetheless, all model parameters are considered genderspecific and separately estimated for men and women.

We denote the marginal effect of a variable $Z$ on choice $j$ for individual $i$ in period $t$ with

$$
\operatorname{ME}_{i j Z, t}\left(\theta^{k}\right)=\frac{\partial F_{j}^{k}\left(X_{i, t}, W L B_{i, t} ; \theta^{k}\right)}{\partial Z_{i, t}}
$$

We estimate and report in the tables below the average marginal effects, that is:

$$
\overline{\mathrm{ME}}_{j Z}\left(\hat{\theta}^{k}\right)=\sum_{i=1}^{N} \sum_{t=1}^{4} D_{i, t} \mathrm{ME}_{i j Z, t}\left(\hat{\theta}^{k}\right) / \sum_{i=1}^{N} \sum_{t=1}^{4} D_{i, t},
$$

where $N$ is the number of individuals in our sample and $D_{i, t}$ is equal to 1 if the transition between waves $t$ and $t+1$ of individual $i$ is in our sample and to 0 otherwise. Standard errors are computed by the delta method and clustered at the individual level, since the same individual $i$ may be represented in multiple observations (from different waves).

\subsection{Regressions by employment status at time $t$ and gender}

Men

The top panel of Table 5 shows the estimated marginal effects for male workers. For men working fulltime at time $t$, more WLI is associated with a lower likelihood of remaining in full-time work and a correspondingly greater probability of retirement at time $t+1$, although the coefficients are not statistically significant. The association is stronger for individuals employed part-time at time $t$ : A one standard deviation higher WLI index is associated with a 7-percentage point lower likelihood of remaining part-time employed at time $t+1$ and a 6-percentage point higher chance of withdrawing from the labor force. The latter constitutes a sizable 27 percent increase relative to the observed 22 percent probability that part-time male workers retire in the next period. 
Table 5: Average marginal effects of Work-Life Interference (WLI) and Life-Work Interference (LWI) on employment transitions

\begin{tabular}{|c|c|c|c|c|c|c|}
\hline & \multicolumn{3}{|c|}{ Transition from full-time to: } & \multicolumn{3}{|c|}{ Transition from part-time to: } \\
\hline & Full-time & Part-time & Retired & Full-time & Part-time & Retired \\
\hline \multicolumn{7}{|l|}{ Men } \\
\hline \multirow[t]{2}{*}{ WLI } & -0.013 & 0.001 & 0.012 & 0.011 & $-0.071 * * *$ & $0.059 * * *$ \\
\hline & $(0.009)$ & $(0.007)$ & $(0.008)$ & $(0.016)$ & $(0.024)$ & $(0.020)$ \\
\hline \multirow[t]{2}{*}{ LWI } & -0.007 & 0.007 & -0.000 & -0.022 & $0.046^{*}$ & -0.024 \\
\hline & $(0.010)$ & $(0.007)$ & $(0.008)$ & $(0.018)$ & $(0.024)$ & $(0.020)$ \\
\hline$N$ & & 2,354 & & & 682 & \\
\hline \multicolumn{7}{|c|}{ Women } \\
\hline \multirow[t]{2}{*}{ WLI } & $-0.020 * *$ & -0.002 & $0.022 * * *$ & 0.003 & $-0.049 * * *$ & $0.046 * * *$ \\
\hline & $(0.010)$ & $(0.007)$ & $(0.008)$ & $(0.010)$ & $(0.016)$ & $(0.014)$ \\
\hline \multirow[t]{2}{*}{ LWI } & -0.009 & 0.008 & 0.001 & -0.014 & $0.030 *$ & -0.016 \\
\hline & $(0.010)$ & $(0.006)$ & $(0.008)$ & $(0.010)$ & $(0.016)$ & $(0.014)$ \\
\hline$N$ & & 2,478 & & & 1,355 & \\
\hline
\end{tabular}

Note. Standard errors clustered at the individual level in parentheses. $* p<0.10$; ${ }^{* *} p<0.05$; $* * *<0.01$. Controls for age, education, couple status, spouse working, poor health, cognition, hh wealth, hours of work, hourly wage, DB and DC pension, health insurance, and time fixed effects included.

Perceived interference from private life to work has no apparent effect on full-timers’ labor supply decisions. This result is consistent with Raymo and Sweeney (2006), who find no significant correlation between LWI and individual stated preferences for early retirement in a sample of full-time workers. For part-timers, a one standard deviation higher LWI is associated with a 4.6 percentage point higher likelihood of remaining in part-time work, but this effect is only marginally significant. Moreover, given that an increase in LWI is, at the same time, associated with a lower likelihood of moving to full-time work and to retirement, it is hard to identify the type of workers that may drive this result. On one side, individuals who find respite at work from their family strains may remain in part-time employment rather than retire. On the other, individuals who would have otherwise transitioned into full-time work may remain in part-time employment to better manage their private life conflicts. 


\section{Women}

Estimates for women are reported in the bottom panel of Table 5. In general, higher WLI is associated with a higher probability of retirement. Specifically, for full-timers, a one standard deviation higher WLI is associated with a 2.2-percentage point higher chance of retirement, a 16 percent increase from the 14 percent sample average. The effect is larger for part-timers. For them, a one standard deviation higher WLI is associated with a 4.6-percentage point higher likelihood of retirement. This represents a 23 percent increase from the 20 percent sample average. As was the case for male workers, there is no association between LWI and labor force transitions for full-timers and only a weak correlation between LWI and the probability that part-timers remain in part-time employment.

\subsection{Interaction between WLB and changes in spouse's health}

The effect of WLB on employment transitions may vary with life circumstances. For instance, a spouse's or elderly parent's health shock may increase the importance of time off for care giving. Individuals whose jobs do not afford them the option to easily juggle family responsibilities may be inclined to reduce their hours of work or exit the labor force following such events. We investigate this hypothesis focusing on the WLI index, which, as shown above, correlates most strongly with labor force transitions, and by interacting it with the onset of a spouse's health shock across two consecutive periods. More precisely, we specify the multinomial logit single index function as follows:

$$
V_{i j}^{k}=X_{i, t}^{\prime} \alpha_{j}^{k}+W L I_{i, t} \beta_{j}^{k}+S p H S_{i, t} \gamma_{j}^{k}+\left(W L I_{i, t} \times S p H S_{i, t}\right) \delta_{j}^{k}
$$

where, again, the superscript $k$ indicates employment status at time $t$ (either full-time, $k=1$, or parttime, $k=2$ ) and the model's parameters are treated as gender-specific. The variable $S p H S_{i, t}$, defined in Section 2, captures the onset of a spouse's acute health issue or newly diagnosed chronic condition between times $t$ and $t+1$. 
We estimate the marginal effects of a spouse's health shock on employment transitions at different levels of WLI. Figures 1 and 2 show the point estimates and the corresponding 95 percent confidence bands by gender and employment status at time $t$. This analysis is complemented with regressions of the individual-level marginal effects of a spouse's health shock on the WLI index, which is a linear smooth of the corresponding graph. The estimated coefficients from these regressions can be interpreted as summary statistics of the extent to which poor WLB interacts with a spouse's health shock to shape retirement paths (i.e., how the likelihood of partially or fully retiring following a spouse's health shock varies with increases in the level of perceived WLI). We adopt a bootstrap procedure (with 500 replications) to compute the standard error of these parameters. This accounts for the estimation error of the first-step multinomial logit marginal effects, which are then used as dependent variables in the second-step regressions.

The left-hand side graphs in Figure 1 show that, for male workers employed full-time, the likelihood of remaining in full-time employment following a spouse's health shock decreases as WLI increases. While a spouse's health shock has no effect on the probability of remaining in full-time work for individuals with the lowest WLI, it is associated with an 18-percentage point decline (significant at 10 percent) for those with the highest WLI. In Table 6, we estimate that, following a spouse's health shock, the probability that men remain in full-time employment decreases by 4.2 percentage points for a one standard deviation increase in the level of WLI. The right-hand side graphs in Figure 1 show that men working part-time at time $t$ respond relatively little to the onset of spousal health issues. Moreover, this response does not vary with the degree of WLI. 
Figure 1: Heterogeneous effects of a spouse's health shock on labor force transitions by Work-Life Interference (WLI): men

Full-time at time $t$

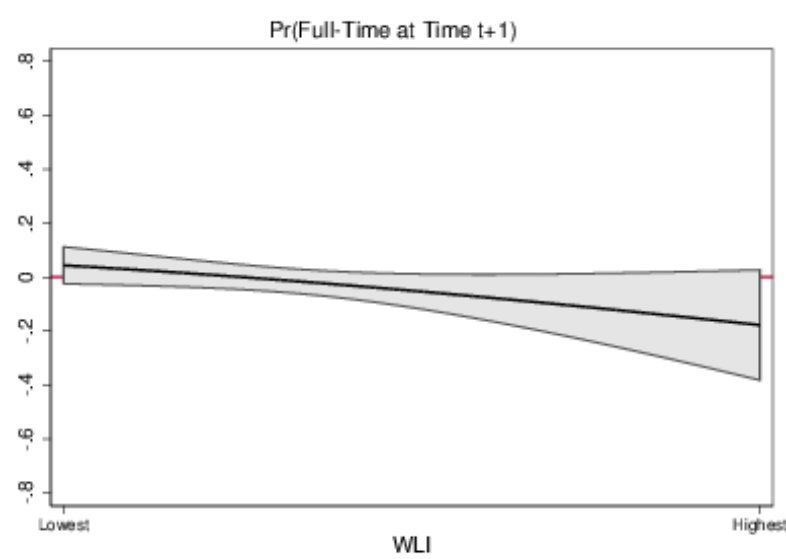

$\operatorname{Pr}(\operatorname{Part}-\mathrm{Time}$ at Time $t+1)$

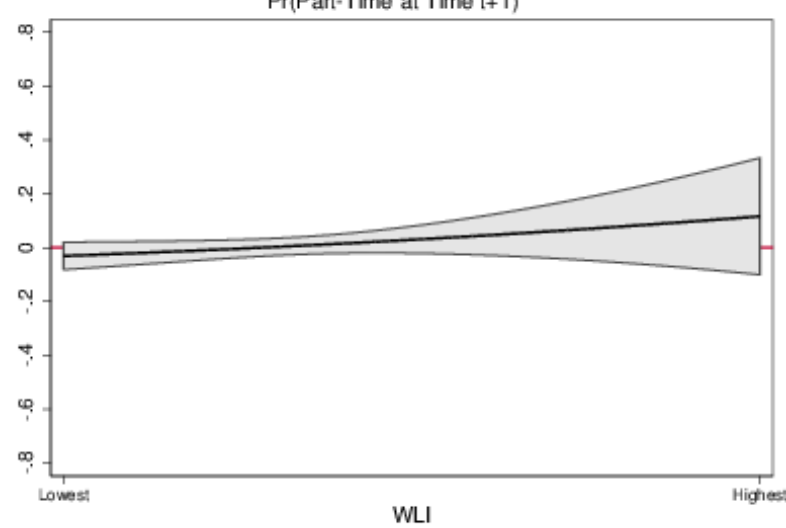

$\operatorname{Pr}($ Retirement at Time $t+1$

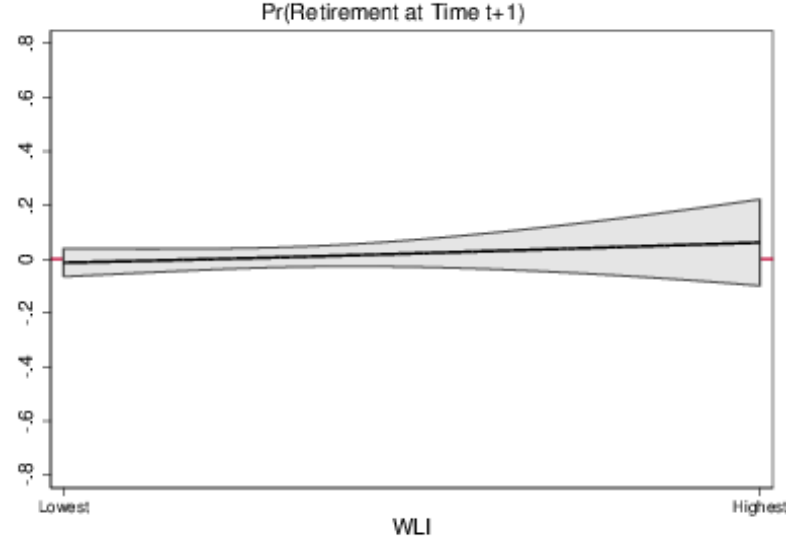

Part-time at time $t$

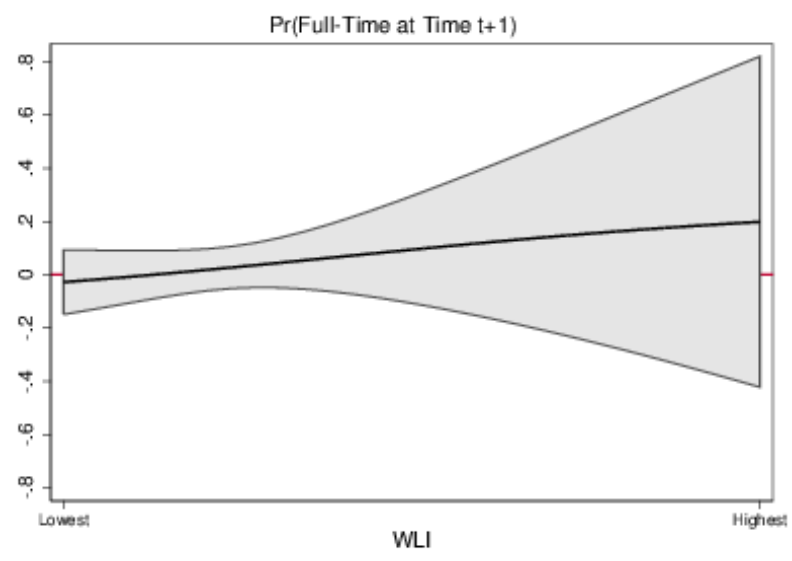

$\operatorname{Pr}(\operatorname{Part}-\mathrm{Time}$ at Time $\mathrm{t}+1)$

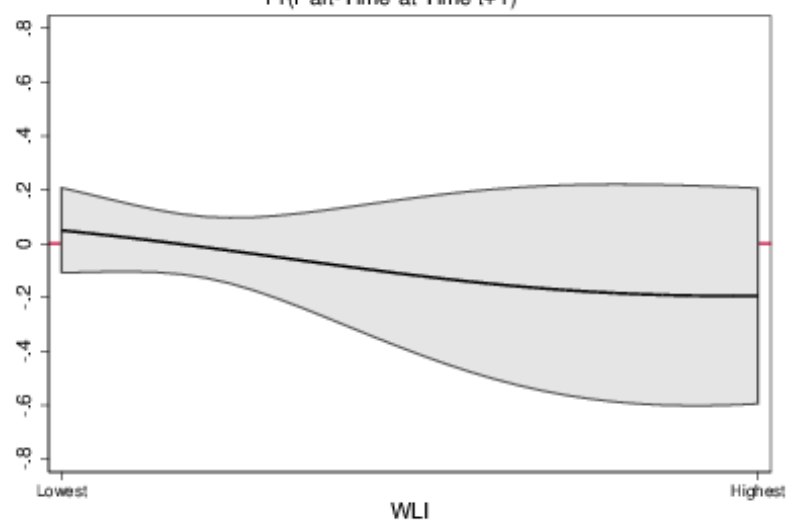

$\operatorname{Pr}($ Retirement at Time $t+1)$

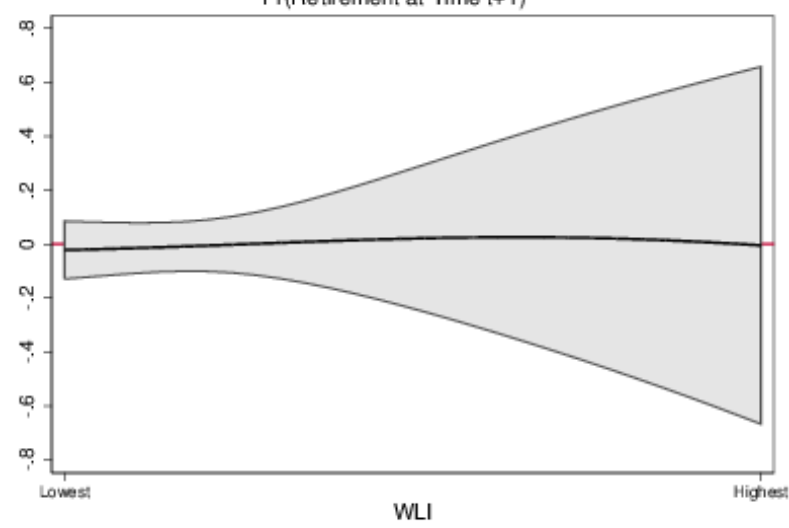


Figure 2: Heterogeneous effects of a spouse's health shock on labor force transitions by Work-Life Interference (WLI): women

Full-time at time $t$

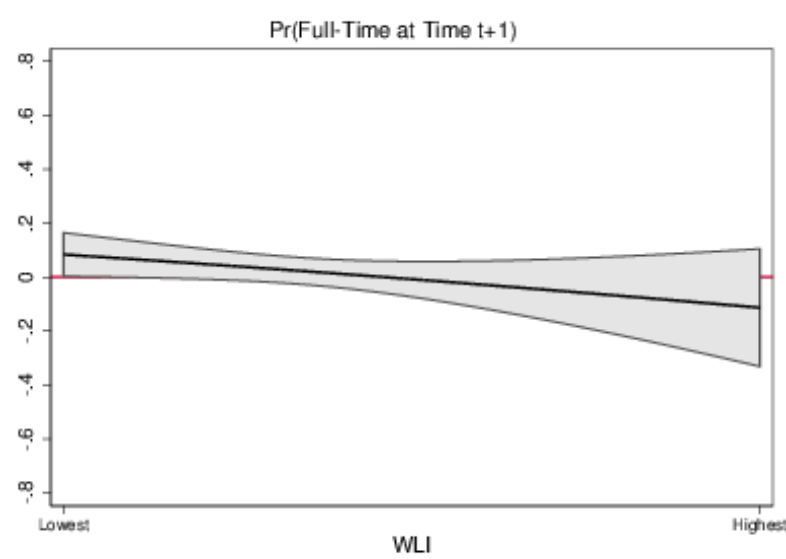

$\operatorname{Pr}(\operatorname{Part}-$ Time at Time $\mathrm{t}+1)$

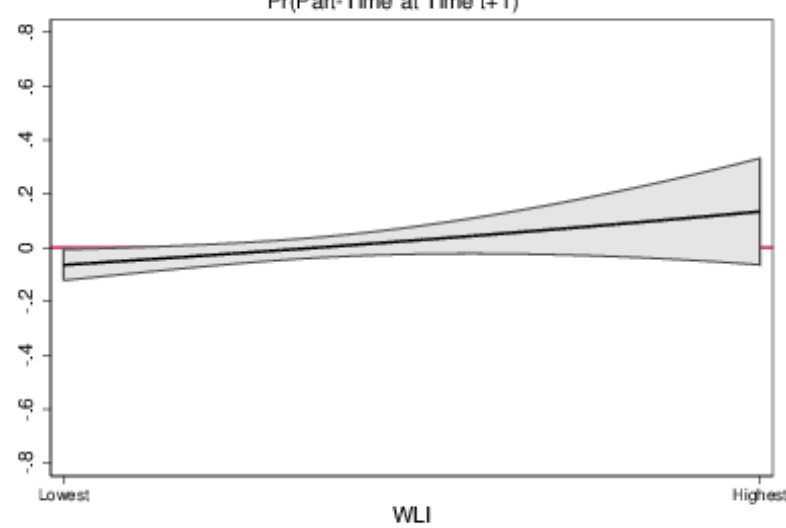

$\operatorname{Pr}($ Retirement at Time $t+1)$

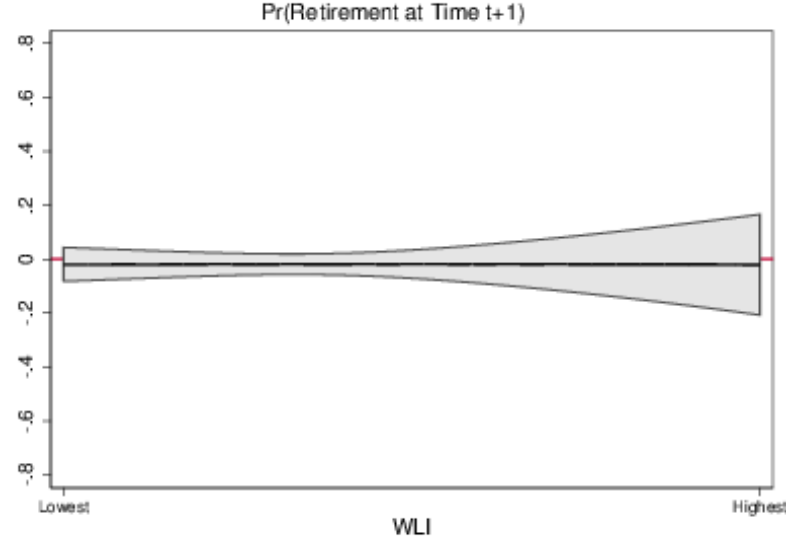

Part-time at time $t$

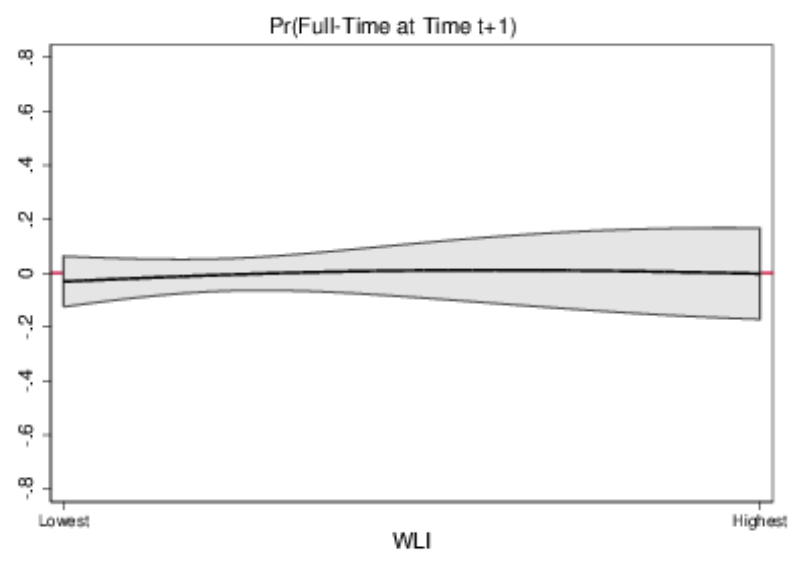

$\operatorname{Pr}($ Part-Time at Time $t+1)$

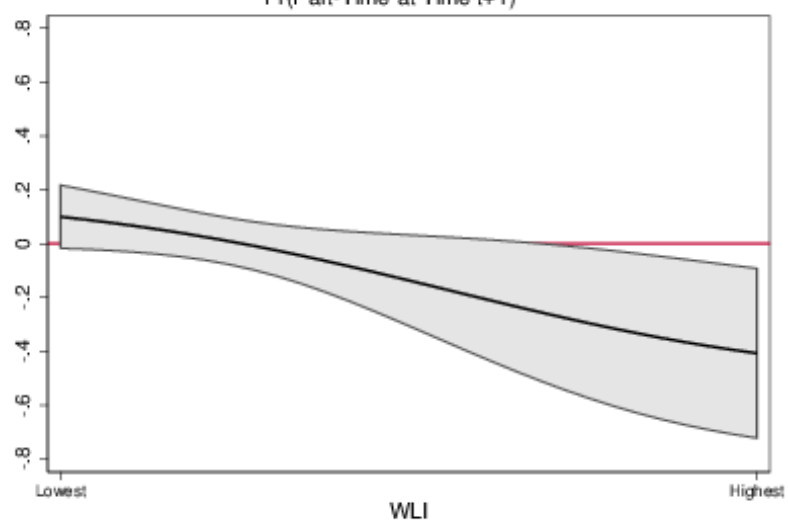

$\operatorname{Pr}($ Retirement at Time $t+1)$

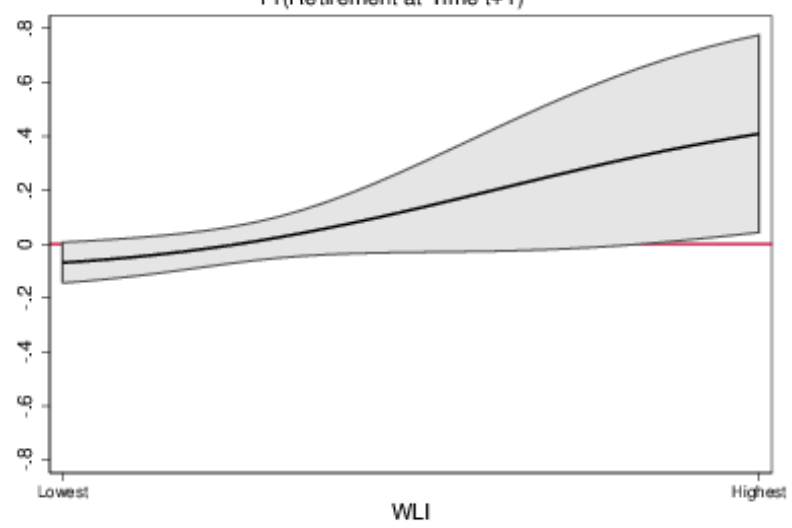


Table 6: Regression of marginal effect of spouse's health shock on WLI (coefficient)

\begin{tabular}{|c|c|c|c|c|c|}
\hline \multirow[t]{2}{*}{ Gender } & \multirow{2}{*}{$\begin{array}{l}\text { Labor force status } \\
\text { at time } t\end{array}$} & \multirow[t]{2}{*}{$N$} & \multicolumn{3}{|c|}{ Transition to: } \\
\hline & & & Full-time & Part-time & Retired \\
\hline \multirow[t]{4}{*}{ Men } & Full-time & 1,889 & $-0.042 *$ & 0.026 & 0.016 \\
\hline & & & $(0.024)$ & $(0.020)$ & $(0.018)$ \\
\hline & Part-time & 554 & 0.045 & -0.057 & 0.013 \\
\hline & & & $(0.053)$ & $(0.064)$ & $(0.048)$ \\
\hline \multirow[t]{4}{*}{ Women } & Full-time & 1,496 & -0.041 & $0.040 * *$ & 0.001 \\
\hline & & & $(0.027)$ & $(0.020)$ & $(0.022)$ \\
\hline & Part-time & 854 & 0.016 & $-0.097 * *$ & $0.080 * *$ \\
\hline & & & $(0.031)$ & $(0.049)$ & $(0.040)$ \\
\hline
\end{tabular}

Note. Bootstrap standard errors (500 replications) clustered at the individual level in parentheses.

${ }^{*} p<0.10$; ** $p<0.05$;** $p<0.01$.

In line with previous studies (Coile, 2004; McGeary, 2009), female workers tend to decrease their labor supply more in response to a spouse’s health shock than their male counterparts. Most importantly, these responses depend on the perceived degree of WLB. The left-hand side graphs in Figure 2 show a very clear WLI-gradient in the effect of a spouse's health shock on labor force transitions of women in full-time work. At low levels of WLI, a spouse's health shock is associated with a 7-percentage point higher likelihood of remaining in full-time employment and, conversely, with a 5-percentage point lower probability of transitioning to part-time employment. As the degree of WLI increases, full-time female workers exhibit a marked tendency to move to part-time after a spouse’s health shock. In general, following a spouse's health shock, the probability that women working full-time at time $t$ switch to parttime at time $t+1$ increases by 4 percentage points for a one standard deviation increase in the WLI index. There is, instead, no evidence of higher fractions of direct transitions from full-time to retirement after the onset of a spouse’s health issues.

As shown in the right-hand side graphs of Figure 2, women working part-time are more likely to respond to a spouse's health shock by withdrawing from the labor force. Again, this response is rather heterogeneous, depending on the current work-life balance situation. At the lowest level of work-to-life 
conflict, female part-timers are 10 percentage points more likely to stay in part-time and 7 percentage points less likely to retire if the spouse developed new acute or chronic conditions. In contrast, those facing the highest degree of WLI are about 35 percentage points less likely to keep working in the following period and about 35 percentage points more likely to retire. Table 6 indicates that, for women working part-time, a spouse’s health shock decreases the probability of remaining in part-time by over 9 percentage points, and increases the likelihood of retirement by 8 percentage points, for a standard deviation increase in the WLI index.

\section{Conclusions}

Work-life balance (WLB) is likely an important determinant of employment decisions. There is ample anecdotal evidence suggesting that workers who perceive that their jobs are an obstacle to the successful management of their private lives are less likely to remain employed. For instance, in middle-aged families where working individuals are responsible both for bringing up their own children and for the care of their aging parents, or in couples approaching retirement age where one of the spouses suffers health problems, a good or bad WLB can make the difference between continuing working or dropping out of the labor force. In this paper, we take on the task of establishing and quantifying the extent to which the degree of perceived WLB influences labor supply decisions among middle-aged and older workers.

Changing retirement patterns over the last few decades mean that retirement can no longer be thought of as a binary choice between full-time work and complete exit from the labor force (Ruhm, 1990; Cahill et al., 2015). A common alternative path is to move to a part-time or bridge job before fully retiring. Partial retirement arrangements are particularly important in the context of our study, as they may afford a better balance between work and family responsibilities, while prolonging individuals’ attachment to the labor force. To allow for the variety of retirement paths nowadays available to individuals, we estimate multinomial discrete choice models for the transitions from full-time 
employment into part-time work and retirement, and for the transitions from part-time employment into full-time work and retirement across two consecutive periods. Moreover, recognizing the existence of potential gender differences in the preference for work versus leisure and household production, as well as in the perception of how work interferes with private life, we separately estimate our models for men and women. Hence, we provide an extensive analysis of employment transitions at older ages, and we document heterogeneity in the extent to which WLB might affect these decisions.

The conflict between work and private life is potentially bidirectional (Frone et al., 1992; Guest, 2002). In our analysis, we distinguish between work-to-life interference (WLI), that is, instances were work demands affect individuals' ability to manage their private lives satisfactorily; and life-to-work interference (LWI), which refers to private life responsibilities that affect job performance and productivity.

We use data from the Health and Retirement Study (HRS), a longitudinal survey representative of the U.S. population older than 50, which provides detailed information about individuals' and couples’ economic status, health, demographics, and job characteristics. Individuals’ perceptions of WLI and LWI are elicited through the Leave-Behind Questionnaire, which is administered to half of the panel in each biennial wave. The richness of the HRS data allows us to study the effects of WLI and LWI on employment transitions jointly, while controlling for a rich set of other determinants ranging from demographics, health, and household wealth to wage, pension plan enrollment, and health insurance benefits.

We find that WLB is significantly associated with employment transitions. This association is mainly driven by WLI, whereas LWI correlates only weakly with labor supply decisions of older workers. There exists substantial heterogeneity in the response to perceived WLB by gender and employment status at baseline. A one standard deviation higher WLI is associated with a 5.9-percentage points higher retirement probability of male part-time workers, a 2.2-percentage points higher retirement probability of female full-time workers, and a 4.6-percentage points higher retirement probability of 
female part-time workers. These effects are sizable, representing a 27 percent, 16 percent, and 23 percent increase relative to the sample average, respectively. WLI does not significantly correlate with employment transitions of male full-time workers, however.

A prime example of a situation in which WLB may tip the scales in favor of continued employment or retirement is when an individual's spouse experiences a health shock. This may lead to new caregiving responsibilities and also affect expectations about mortality, which in itself may alter the relative utility of work versus leisure. We show that WLB moderates labor supply responses to a spouse's health shock and differentially so for men and women. For men, the probability of remaining in full-time employment following a spouse's health shock decreases by 4.2 percentage points for a one standard deviation increase in the level of WLI. This gradient, however, is only significant at 10 percent. Moreover, there is no moderating effect of WLI for part-timers. For women in full-time employment, the probability of switching to a part-time job following a spouse's health shock increases by 4 percentage points with a one standard deviation increase in WLI. For those employed part-time, the probability of retirement is 8 percentage points higher for a one standard deviation increase in the WLI index.

A limitation of our study is that, while controlling for a wide array of variables that may affect both WLB and employment transitions, we cannot completely rule out that other, unobservable factors may drive the estimated relations between WLB and labor supply decisions. Because of that, we have refrained from making causal claims throughout the text. Such factors plausibly comprise individual aptitudes and preferences underlying selection into jobs with certain characteristics, including level of WLB, as well as tastes for mode and timing of retirement. However, these individual traits would likely bias our parameters of interest downward, and hence toward the null hypothesis of no relationship between WLB and employment transitions. We would expect individuals who have a stronger preference for leisure over work to have a higher likelihood of selecting into jobs with better WLB and to retire earlier, other things equal. This selection mechanism would imply that individuals with better 
WLB would be more prone to reduce their labor supply. Our findings that worse WLB is associated with a higher likelihood of transiting into partial and full retirement contradict this argument, and are suggestive of a causal, positive link between WLB and prolonged attachment to the labor force.

The institutional framework where individuals work is bound to affect experienced work-life balance. Laws that make it mandatory for employers to facilitate part-time employment or paid leave opportunities to help employees juggle family responsibilities may improve WLB and, in turn, facilitate longer labor force attachment of older workers. Policy changes affecting the work flexibility of some workers and not of others (e.g., paid family leave insurance laws becoming effective in California, New Jersey, Rhode Island, and Washington between 2004 and 2019) may also be exploited to infer stronger and more robust causal relationships between WLB and employment transitions. ${ }^{3}$ We leave this for future research. 


\section{References}

Angrisani, M., M. D. Hurd, E. Meijer, A. M. Parker, and S. Rohwedder (2017). Personality and employment transitions at older ages: Direct and indirect effects through non-monetary job characteristics. Labour 31, 127-152.

Angrisani, M., A. Kapteyn, and E. Meijer (2015). Nonmonetary job characteristics and employment transitions at older ages. Working Paper WP 2015-326, University of Michigan Retirement Research Center, Ann Arbor, MI.

Bianchi, S. M. and M. A. Milkie (2010). Work and family research in the first decade of the 21st century. Journal of Marriage and Family 72, 705-725.

Blau, D. and R. M. Goodstein (2010). Can social security explain trends in labor force participation of older men in the united states? Journal of Human Resources 45, 328-363.

Bugliari, D. et al. (2016). RAND HRS Data Documentation, Version P. Santa Monica, CA: RAND Corporation, Center for the Study of Aging. http://hrsonline.isr.umich.edu/modules/meta/rand/index.html.

Cahill, K. E., M. D. Giandrea, and J. F. Quinn (2015). Retirement patterns and the macroeconomy, the prevalence and determinants of bridge jobs, phased retirement, and reentry among three recent cohorts of older americans. Gerontologist 55, 384-403.

Chan, S. and A. H. Stevens (2008). Is retirement being remade? Developments in labor market patterns at older ages. In J. Ameriks and O. S. Mitchell (Eds.), Recalibrating Retirement Spending and Saving, pp. 13-28. Oxford, UK: Oxford University Press.

Clark, A. E. and A. J. Oswald (1996). Satisfactoin and comparison income. Journal of Public Economics 61, 359-381.

Coile, C. C. (2004). Health shocks and couples’ labor supply decisions. Working Paper 10810, National Bureau of Economic Research, Cambridge, MA.

Currie, J. and B. C. Madrian (1999). Health, health insurance and the labor market. In O. Ashenfelter and D. Card (Eds.), Handbook of Labor Economics, Volume 3, pp. 3309-3407. Amsterdam: Elsevier.

Flabbi, L. and A. Moro (2012). The effect of job flexibility on female labor market outcomes: Estimates from a search and bargaining model. Journal of Econometrics 168, 81-95.

French, E. (2005). The effects of health, wealth, and wages on labour supply and retirement behaviour. Review of Economic Studies 72, 395-427.

French, E. and J. B. Jones (2011). The effects of health insurance and self-insurance on retirement behavior. Econometrica 79, 693-732.

Frone, M. R., M. Russell, and M. L. Cooper (1992). Prevalence of work-family conflict: Are work and family boundaries asymmetrically permeable? Journal of Organizational Behavior 13, 723-729.

Gardiner, J., M. Stuart, C. Forde, I. Greenwood, R. MacKenzie, and R. Perrett (2007). Work life balance and older workers: Employees' perspectives on retirement transitions following redundancy. International Journal of Human Resource Management 18, 476-489.

Goda, G. S., D. Jones, and C. F. Manchester (2017). Retirement plan type and employee mobility. the role of selection. Journal of Human Resources 52, 654-679. 
Gruber, J. and D. A. Wise (Eds.) (2004). Social Security Programs and Retirement around the World: Micro-Estimation. Chicago, IL: University of Chicago Press.

Guest, D. E. (2002). Perspectives on the study of work-life balance. Social Science Information 41, 255279.

Lévy-Garboua, L., C. Montmarquette, and V. Simonnet (2007). Job satisfaction and quits. Labour Economics 14(2), 251-268.

Lewis, J. (2008). Work-family balance policies: Issues and development in the UK 1997-2005 in comparative perspective. In J. Scott, S. Dex, and H. Joshi (Eds.), Women and Employment: Changing Lives and New Challenges, pp. 268-288. Cheltenham, UK: Edward Elgar.

Lumsdaine, R. L. and O. S. Mitchell (1999). New developments in the economic analysis of retirement. In O. Ashenfelter and D. Card (Eds.), Handbook of Labor Economics, Volume 3, pp. 3261-3307. Amsterdam: Elsevier.

Maestas, N. (2010). Back to work: Expectations and realizations of work after retirement. Journal of Human Resources 45, 718-748.

McClellan, M. B. (1998). Health events, health insurance, and labor supply: Evidence from the Health and Retirement Survey. In D. A. Wise (Ed.), Frontiers in the Economics of Aging, pp. 301-350. Chicago, IL: University of Chicago Press.

McGeary, K. A. (2009). How do health shocks influence retirement decisions? Review of Economics of the Household 7, 307-321.

Peiperl, M. and B. Jones (2001). Workaholics and overworkers: Productivity or pathology? Group \& Organization Management 26, 369-393.

Raymo, J. M. and M. M. Sweeney (2006). Work-family conflict and retirement preferences. The Journals of Gerontology Series B: Psychological Sciences and Social Sciences 61, S161-S169.

Rossin-Slater, M., C. J. Ruhm, and J. Waldfogel (2013). The effects of California's paid family leave program on mothers' leave-taking and subsequent labor market outcomes. Journal of Policy Analysis and Management 32, 224-245.

Ruhm, C. J. (1990). Bridge jobs and partial retirement. Journal of Labor Economics 8, 482-501.

Smith, J. P. (2005). Consequences and predictors of new health events. In D. A. Wise (Ed.), Analyses in the Economics of Aging, pp. 213-237. Chicago, IL: University of Chicago Press.

Sullivan, P. and T. To (2014). Search and nonwage job characteristics. Journal of Human Resources 49, 472-507.

Wise, D. A. (2010). Facilitating longer working lives: International evidence on why and how. Demography 47, S131-S149. 